Short communication

\title{
PREVALENCE OF CLOSTRIDIUM PERFRINGENS TYPE A ISOLATES IN DIFFERENT TISSUES OF BROILER CHICKENS
}

\author{
A. DOOSTI ${ }^{1}$, M. PASAND $^{2}$, A. MOKHTARI-FARSANI ${ }^{1,3}$, \\ R. AHMADI ${ }^{1} \&$ M. CHEHELGERDI ${ }^{1}$
}

${ }^{1}$ Biotechnology Research Center; ${ }^{2}$ Member of Scientific Association of Microbiology; ${ }^{3}$ Young Researchers and Elite Club; Islamic Azad University, Shahrekord Branch, Shahrekord, Iran

\begin{abstract}
Summary
Doosti, A., M. Pasand, A. Mokhtari-Farsani, R. Ahmadi \& M. Chehelgerdi, 2017. Prevalence of Clostridium perfringens type A isolates in different tissues of broiler chickens. Bulg. J. Vet. Med., 20, No 1, 80-86.

Clostridium perfringens (C. perfringens) is an important pathogen in both human and veterinary medicine. Necrotic enteritis is the most severe clinical bacterial enteric disease of poultry induced by C. perfringens. Study was done on 100 broiler chickens (400 different tissues of chickens) in Southwest Iran. C. perfringens was isolated from different tissues of chickens (meats, liver, gizzard and intestine) using bacterial culture methods. DNA extraction from grown colonies was carried out by boiling method and finally, PCR assay was used for definitive diagnosis of type A C. perfringens. The results of present study showed that from 400 different tissues of chickens $169(42.25 \%)$ samples were positive for $C$. perfringens infection that is a comparatively high prevalence of $C$. perfringens. The highest rate of $C$. perfringens infection in tissues was in intestine $(55 \%)$ and meat (42\%). The high prevalence of type A C. perfringens in different tissues observed in the present study is very disturbing, as it can cause irreparable damage to the poultry industry and human health.
\end{abstract}

Key words: broiler chickens, chicken tissue, type A Clostridium perfringens

Clostridium perfringens (C. perfringens) is a Gram-positive, spore-forming, rod shaped anaerobic non-motile pathogen that is frequently found in the intestinal tract of humans and animals (Obrien \& Melville, 2000). It is commonly present in the environment (in soil, on the skin and sewage) (Shimizu et al., 2002) and is found in undercooked or improperly sterilised canned foods (germination of endospores) and in water (surface water). The natural contamination source are human and animal faeces transmitted into water and food products. Owing to its ability to produce spores under adverse environmental conditions, it is one of the 
most widespread potential bacterial pathogens in nature as well as in the gastrointestinal tract of most animal species (Mokhtari-Farsani \& Doosti, 2015).

$C$. perfringens has been identified as an anaerobe responsible for a wide range of diseases in human and animals (Yoo et al., 1997). This bacterium was first implicated as a cause of antibiotic-associated diarrhoea (AAD) in 1984 (Asha \& Wilcox, 2002). C. perfringens is commonly involved in diseases in most domestic animals and some wildlife, including horses, poultry, birds, rabbits, sheep, goats, cattle, mink, ostriches, dogs and cats (Effat et al., 2007). The overgrowth of $C$. perfringens causes necrotic enteritis (NE) disease in the small intestine of broiler chickens throughout the world. The disease usually occurs in broiler chickens 2 to 6 weeks after hatching (Drew et al., 2004). The virulence of this bacterium largely results of its ability to produce at least 15 different $C$. perfringens toxins (Jabbari et al., 2012). C. perfringens strains are classified into five groups (types A, B, C, D and E) on the basis of their production of four major toxins known as alpha (CPA), beta (CPB), epsilon (ETX), and iota (ITX) toxins (Shimizu et al., 2002).

$C$. perfringens type A food poisoning is one of the most common food borne diseases in the United States. The factor responsible has been shown by the characteristic disease symptoms (diarrhoea and abdominal cramps) of $C$. perfringens food poisoning (Wnek et al., 1985). This type of $C$. perfringens was reported as the cause of necrotic enteritis in poultry especially in broiler chickens (Lindstrom et al., 2011; Rahimi et al., 2011). C. perfringens types $\mathrm{B}$ and $\mathrm{C}$ disease begins in the host intestine (Uzal et al., 2010). Type $\mathrm{B}$ isolates cause an often fatal haemor- rhagic dysentery in sheep, and possibly in other species, while type $\mathrm{C}$ isolates cause enteritis necroticans (also called pigbel) in humans and necrotic enteritis and/or enterotoxaemia in almost all livestock species. Both types B and $\mathrm{C}$ animal disease are often accompanied by sudden death or acute neurological signs (Uzal et al., 2010). Clinical signs and histopathologic findings in type $\mathrm{C}$ infections are very similar in most livestock animal species. The course of disease can be peracute, acute, or chronic, with signs of the acute and peracute condition including intense abdominal pain, depression, and bloody diarrhoea (Songer, 1998). Type B and D strains are causative agents of fatal enterotoxaemia in domestic animals and occasionally humans (Jabbari et al., 2011).

C. perfringens is usually considered to be an exclusively extracellular pathogen that secretes powerful cytotoxins that lyse cells and break down connective tissue (Obrien \& Melville, 2000). After the entry of vegetative cells or spores into the body, the organisms grow rapidly in the host tissue, and produce various toxins and enzymes that cause massive destruction of the host tissues (Rood, 1998).

Due to their short reproductive cycle and their worldwide popularity as a food, poultry represent the most highly selected livestock. Selection of broiler chickens (chickens grown for their meat) has been primarily directed at economic traits which have reduced costs of production (Knowles et al., 2008). Throughout the world the majority of broilers are reared using very similar, modern, intensive systems of production where birds are confined for their lifetime within high density housing (Knowles et al., 2008). The $C$. perfringens type A infections in poultry may present as acute clinical disease or subclinical disease. This organism is asso- 
ciated with necrotic enteritis, gangrenous dermatitis, clostridial dermatitis, and gizzard erosions in poultry (Rahimi et al., 2011). The acute form of the disease leads to increased mortality in the broiler flocks (Immerseel et al., 2004).

Since the understanding of the pathogenicity and physiology of $C$. perfringens is still poor compared with other pathogenic bacteria and by reason of the importance of this bacterium in the poultry industry and human nutrition, the purpose of present research was to study the frequency of $C$. perfringens type A infection by culturing methods and PCR in different tissues of broiler chickens in Chaharmahal Va Bakhtiari province (southwestern Iran).

In the present study, 100 broiler chickens suspicious to be infected with $C$. perfringens (with signs of enteritis) were obtained from ten locations between May to August 2014 from Chaharmahal Va Bakhtiari province located in southwest of Iran and were tested for detection of $c p A$ gene of $C$. perfringens. Their body weight ranged from 150 to $500 \mathrm{~g}$ and their age between 2 to 6 weeks. Initially cooked meat broth medium (Merckoplate, Germany) was prepared in sterile tubes by mixture of $500 \mathrm{mg}$ of cooked meat with $10 \mathrm{~mL}$ distilled water and was heated at $80^{\circ} \mathrm{C}$ for $5 \mathrm{~min}$ in bain marie. Five $\mathrm{g}$ of individual chicken tissues samples (100 from meat, 100 from liver, 100 from gizzard and 100 from intestine) were mixed with $5 \mathrm{~mL}$ of PBS (phosphate buffer) in a sterile mortar separately. The above suspension was added to the cooked meat broth medium and heated at $65{ }^{\circ} \mathrm{C}$ for $10 \mathrm{~min}$ in order to select bacterial spores. Then, tubes were incubated for $72 \mathrm{~h}$ at $37{ }^{\circ} \mathrm{C}$ in an anaerobic $\mathrm{CO}_{2}$ incubator (Finetech, Germany). In the next step each sample were cultured by streak plate method using a sterile loop on already prepared blood agar (Merckoplate, Germany) plates supplemented with 5\% sheep blood and was incubated for $18 \mathrm{~h}$ at $37^{\circ} \mathrm{C}$ under anaerobic conditions. The circular, disordered, flat and bright colonies were indicative for the presence of Clostridium (Doosti \& Mokhtari-Farsani, 2014).

DNA extraction was performed by boiling method. A few colonies were scratched of the blood agar plates, dissolved in $200 \mu \mathrm{L}$ distilled water in test tubes, and were incubated in boiling water bath for 10-15 min. The last step was a 12,000 rpm centrifugation for $5 \mathrm{~min}$, and DNA samples were kept at $-20{ }^{\circ} \mathrm{C}$ until used. PCR method was used for definitive diagnosis of $C$. perfringens. Detection of $C$. perfringens was performed by amplification with the following primers: C.P-F: 5'-GTTGATAGCGCAGGACATGTT AAG-3' and C.P-R: 5'-CATGTAGTC ATCTGTTCCAGC ATC-3' [Gene Bank: KF914160.1]. The PCR reactions were performed in a total volume of $25 \mu \mathrm{L}$ in $0.2 \mathrm{~mL}$ tubes containing $60 \mathrm{ng}$ of DNA sample, $1 \mu \mathrm{M}$ of each primers, $5 \mu \mathrm{L}$ of $10 \times$ PCR buffer AMS, $200 \mu \mathrm{M}$ dNTPs, $2 \mathrm{mM} \mathrm{MgCl}_{2}$ and 1 unit of Taq DNA polymerase (CinnaGen Co, Iran). The PCR reaction mixtures were placed in an Eppendorf PCR thermal cycler (Eppendorf, Hamburg, Germany). Amplification was obtained with 32 cycles following an initial denaturation step at $95{ }^{\circ} \mathrm{C}$ for $5 \mathrm{~min}$. Each cycle comprised denaturation at $94{ }^{\circ} \mathrm{C}$ for $40 \mathrm{~s}$, annealing at $58{ }^{\circ} \mathrm{C}$ for $40 \mathrm{~s}$, and extension at $72{ }^{\circ} \mathrm{C}$ for $60 \mathrm{~s}$. The final extension step was carried out at $72{ }^{\circ} \mathrm{C}$ for $5 \mathrm{~min}$.

The PCR-amplified products ( $c p A$ gene, 602 bp) were analysed by electrophoresis in a $1 \%$ agarose-ethidium bromide gel. Aliquots of $10 \mu \mathrm{L}$ of PCR products were applied to the gel. Constant 
voltage of $90 \mathrm{~V}$ for $20 \mathrm{~min}$ was used for products separation. The PCR products were identified by 100 bp DNA size marker (Fermentas, Germany). After electrophoresis, the gel was examined under ultraviolet illumination and photo was obtained using a UVI doc gel documentation systems (UK).

All data for determination of frequency of $C$. perfringens infection in different tissues of broiler chickens were analysed by the chi-square test using the SPSS 17 (SPSS Inc. Chicago, IL, USA) software. $\mathrm{P}$ values $<0.05$ were considered significant.

From 400 samples, 223 samples (55.75\%) were positive for Clostridium by bacterial culture method. After culture of C. perfringens and DNA extraction, the quality of the extracted DNA was examined through $1 \%$ agarose gel and was confirmed. All isolates were examined for the presence of the $c p A$ gene by PCR. Agarose gel electrophoresis of positive samples revealed a 602 bp fragment (Fig. 1). The results showed that from 100 broiler chickens 55 were infected with type A $C$. perfringens. Overall, 169 of the 400 $(42.25 \%)$ tissues were positive for $C$. perfringens by PCR assay. The rate of $C$. perfringens infection in different tissues of chickens was $42 / 100$ for meat, 55/100 for intestine, $34 / 100$ for gizzard and $38 / 100$ for liver.

Although $C$. perfringens is a member of normal gut flora, it is also regarded as one of the most important causes of intestinal disease in farm animals and wild

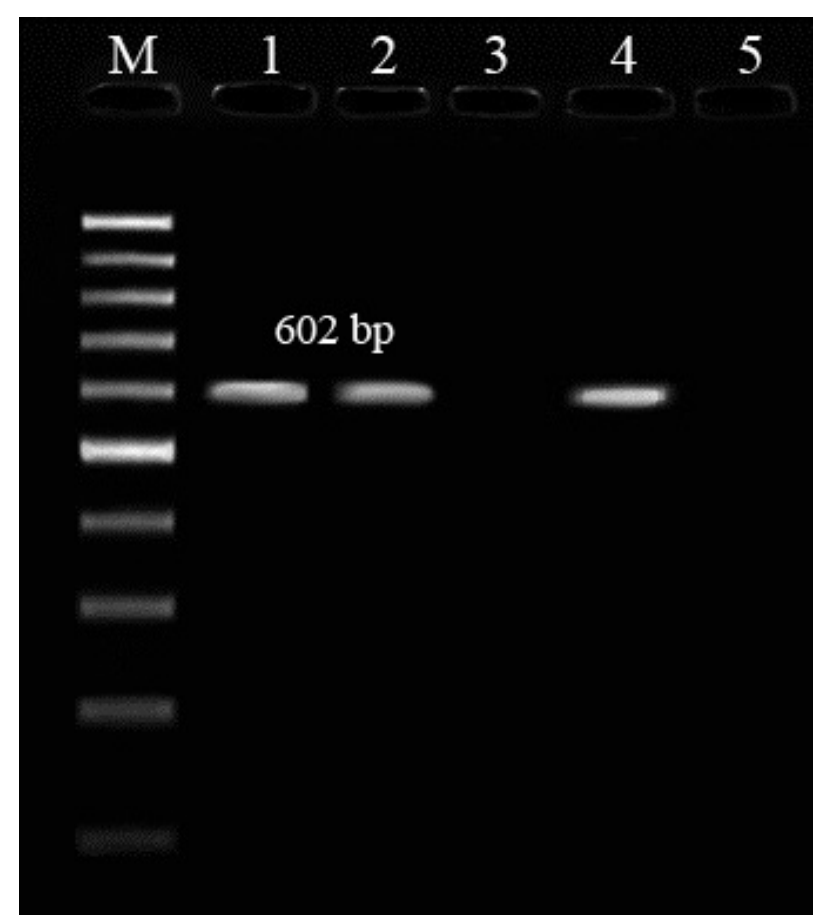

Fig. 1. Agarose gel electrophoresis of PCR amplification products for detection of C. perfringens in broiler chickens samples. Lane M: Fermentas 100-bp DNA molecular marker, lanes 1, 2 and 4 are positive samples, lane 3: negative sample, lane 5: negative control. 
animals and, to a lesser extent, in humans (Allaart et al., 2011). C. perfringens plays a significant role in food-borne human disease and is among the most common food-borne illnesses in industrialised countries (Brynestad \& Granum, 2002; Lindstrom et al., 2011). Since C. perfringens food poisoning is not a reportable disease, its frequency probably is seriously underestimated. Nonetheless, in recent years a high incidence of $C$. perfringens food poisoning in different country like Japan, Norway, the UK and the USA was reported (Immerseel et al., 2004). If a sufficient number of $C$. perfringens cells are consumed with contaminated food, these cells are capable to pass from the stomach to the intestinal tract where spores are produced, released and cause clinical $C$. perfringens food poisoning (Smedley et al., 2004; Sawires \& Songer, 2006).

The broiler chicken industry is a main source of animal protein and fat (Mersmann, 2002), and C. perfringens is considered as a serious threat to this industry. In the present study a relatively high prevalence of $C$. perfringens infections $(42.25 \%)$ in different tissues of broiler chickens was observed. Some studies were performed about $C$. perfringens infection in broiler chickens. In study of Miwa et al. (1997) the reported prevalence of $C$. perfringens in chicken intestinal contents was $40 \%$ that is somewhat similar to the present study results. Studies conducted on incidence of $C$. perfringens in meat and the intestinal tract of poultry between 1996 to 2001 established that approximately $75 \%$ to $95 \%$ of the animals were positive, with a remarkable high percentages of positive meat samples (up to 84\%) (Immerseel et al., 2004). Perhaps the reason for very high incidence in this study and for the difference with the results of our study is the general detection of all C. perfringens types, as we used specific primers only for diagnosis of type A $C$. perfringens. In the investigation of Craven et al. (2001) on environmental samples collected from poultry farms, the prevalence of $C$. perfringens was between $43 \%$ to $53 \%$ indicating that $C$. perfringens is a common intestinal inhabitant. Obviously, in our study and other studies throughout the world the incidence of $C$. perfringens in poultry industry was high. Also, the present results and those from other studies showed that $C$. perfringens can easily spread from the intestine to other tissues of broiler chickens, and that the global prevalence of $C$. perfringens in chicken meat of $40 \%$ to $84 \%$ is a threat for human health and the poultry industry.

Despite of the known protective effects in other animal species, vaccination of poultry against $C$. perfringens is a seriously under-researched matter. It is documented in numerous studies that coccidiostatic drugs and coccidial vaccines are able to prevent $C$. perfringens-associated necrotic enteritis (Immerseel et al., 2004). As to the results of studies indicating successful use of vaccines in other farm animals, vaccination could be a helpful tool in preventing $C$. perfringens infection and necrotic enteritis in poultry. In addition to vaccination, the use of probiotics has been found effective against various pathogens especially $C$. perfringens in poultry (Asadi-Farsani et al., 2015).

Our study and other studies shows a high prevalence of $C$. perfringens in broiler chickens. The present study established a relatively high prevalence of this bacterium in meat (42\%) (which is related to human nutrition) compared to other tissues according to their importance in human nutrition. In conclusion, to prevent 
the increasing growth of $C$. perfringens and further damage to the poultry industry and most importantly transmission of this pathogen from poultry to humans, we suggest regular vaccination, use of probiotics in poultry diets, use of appropriate antibiotics and reduction of imprudent use of antibiotics in order to avoid microbial resistance, and further studies for recognition of the epidemiology of this bacterium.

\section{ACKNOWLEDGMENTS}

The authors would like to thank all the staff at the Biotechnology Research Center of the Islamic Azad University of Shahrekord for their important technical and clinical support.

\section{REFERENCES}

Allaart, J. G., A. J. A. M. Van Asten, J. C. M. Vernooij, \& A. Grone, 2011. Effect of Lactobacillus fermentum on beta2 toxin production by Clostridium perfringens. Applied and Environmental Microbiology, 77, 4406-4411.

Asadi-Farsani, K., A. Doosti, \& A. MokhtariFarsani, 2015. Cloning and sequencing of xylanase gene from Bacillus subtilis. Research Opinions in Animal \& Veterinary Sciences, 5, 215-218.

Asha, N. J. \& M. H. Wilcox, 2002. Laboratory diagnosis of Clostridium perfringens antibiotic-associated diarrhea. Journal of Medical Microbiology, 51, 891-894.

Brynestad, S. \& P. E. Granum, 2002. Clostridium perfringens and foodborne infections. International Journal of Food Microbiology, 74, 195-202.

Craven, S. E., N. J. Stern, J. S. Bailey, \& N. A. Cox, 2001. Incidence of Clostridium perfringens in broiler chickens and their environment during production and processing. Avian Diseases, 45, 887-896.
Doosti, A. \& A. Mokhtari-Farsani, 2014 Study of the frequency of Clostridium difficile $t c d A, t c d B, c d t A$ and $c d t B$ genes in feces of calves in south west of Iran. $A n$ nals of Clinical Microbiology and Antimicrobials, 13, 21.

Drew, M. D., N. A. Syed, B. G. Goldade, B. Laarveld, \& A. G. Van Kessel, 2004. Effects of dietary protein source and level on intestinal populations of Clostridium perfringens in broiler chickens. Poultry Science, 83, 414-420.

Effat, M. M., Y. A. Abdallah, M. F. Soheir, \& M. M. Rady, 2007. Characterization of Clostridium perfringens field isolates, implicated in necrotic entritis outbreaks on private broiler farms in Cairo, by multiplex PCR. African Journal of Microbiology Research, 29-32.

Immerseel, F. V., J. D. Buck, F. Pasmans, G. Huyghebaert, F. Haesebrouck, \& R. Ducatelle, 2004. Clostridium perfringens in poultry: An emerging threat for animal and public health. Avian Pathology, 33, 537-549.

Jabbari, A. R., A. R. Afshari Far, M. Esmaelizad, R. Pilehchian Langroudi, \& L. Abdolmohammadi Khiav, 2011. Molecular typing of toxigenic Clostridium perfringens isolated from sheep in Iran. Archives of Razi Institute, 66, 81-86.

Jabbari, A. R., F. Tekyei, M. Esmaeilizad, \& R. Pilehchian Langroudi, 2012. Occurrence of Beta2 toxigenic Clostridium perfringens isolates with different toxin types in Iran. Archives of Razi Institute, 67, 133137.

Knowles, T. G., S. C. Kestin, S. M. Haslam, S. N. Brown, L. E. Green, A. Butterworth, S. J. Pope, D. Pfeiffer, \& C. J. Nicol, 2008. Leg disorders in broiler chickens: Prevalence, risk factors and prevention. PLoS One, 3, 1545.

Lindstrom, M., A. Heikinheimo, P. Lahti, \& H. Korkeala, 2011. Novel insights into the epidemiology of Clostridium perfringens type A food poisoning. Food Microbiology, 28, 192-198. 
Mersmann, H. J., 2002. Beta-adrenergic receptor modulation of adipocyte metabolism and growth. Journal of Animal Science, 80, 24-29.

Miwa, N., T. Nishina, S. Kubo, \& H. Honda, 1997. Most probable numbers of enterotoxigenic Clostridium perfringens in intestinal contents of domestic livestock detected by nested PCR. Journal of Veterinary Medical Science, 59, 557-560.

Mokhtari-Farsani, A. \& A. Doosti, 2015. Investigation of antibiotic resistance and frequency of Clostridium difficile tcdA and tcdB genes in feces of calves in Chaharmahal Va Bakhtiari province. Journal of Shahrekord University of Medical Sciences, 17, 35-42.

Obrien, D. K. \& S. B. Melville, 2000. The anaerobic pathogen Clostridium perfringens can escape the phagosome of macrophages under aerobic conditions. Cellular Microbiology, 2, 505-519.

Rahimi, S., S. Kathariou, J. L Grimes, \& R. M. Siletzky, 2011. Effect of direct-fed microbials on performance and Clostridium perfringens colonization of turkey poults. Poultry Science, 90, 2656-2662.

Rood, J. I., 1998. Virulence genes of Clostridium perfringens. Annual Review of Microbiology, 52, 333-360.

Sawires, Y. S. \& J. G. Songer, 2006. Clostridium perfringens: Insight into virulence evolution and population structure. Anaerobe, 12, 23-43.

Shimizu, T., K. Ohtani, H. Hirakawa, K. Ohshima, A. Yamashita, T. Shiba, N. Ogasawara, M. Hattori, S. Kuhara, \& H. Hayashi, 2002. Complete genome sequence of Clostridium perfringens, an anaerobic flesh-eater. Proceedings of the National Academy of Sciences, 99, 996-1001.
Smedley, J. G., D. J. Fisher, S. Sayeed, G. Chakrabarti, \& B. A. McClane, 2004. The enteric toxins of Clostridium perfringens. Reviews of Physiology, Biochemistry and Pharmacology, 152, 183-204.

Songer, J. G., 1998. Clostridial diseases of small ruminants. Veterinary Research, 29, 219-232.

Uzal, F. A., J. E. Vidal, B. A. McClane, \& A. A. Gurjar, 2010. Clostridium perfringens toxins involved in mammalian veterinary diseases. Open Toxin Journal, 3, 24-42.

Wnek, A. P., R. J. Strouse, \& B. A. McClane, 1985. Production and characterization of monoclonal antibodies against Clostridium perfringens type A enterotoxin. Infection and Immunity, 50, 442-448.

Yoo, H. S., S. U. Lee, K. Y. Park, \& Y. H. Park, 1997. Molecular typing and epidemiological survey of prevalence of Clostridium perfringens types by multiplex PCR. Journal of Clinical Microbiology, 35, 228-232.

Paper received 16.04.2015; accepted for publication 15.06.2015

\section{Correspondence:}

Abbas Doosti (Ph.D Molecular Genetics)

Biotechnology Research Center,

Islamic Azad University,

Shahrekord Branch, Shahrekord, Iran,

Postal box: 166,

Tel: +98-381-3361001,

Fax: +98-381-3361001,

e-mail: geneticsshki@yahoo.com 